\title{
Economia e cultura: um estudo aplicado no município de Goiás
}

\section{Aline Tereza Borghi Leite ${ }^{1}$ Juliano de Castro Silvestre ${ }^{2}$}

Resumo: Este artigo aborda as relações econômicas e culturais numa perspectiva de desenvolvimento local e regional aplicado no município de Goiás, considerado de médio porte no estado. Em 2016, a Economia Criativa representou aproximadamente 2,6\% do PIB brasileiro além de apresentar um crescimento de cerca de $70 \%$ nos últimos dez anos. Quanto mais investimento público ou privado neste novo segmento econômico, menor é o fluxo migratório de pessoas em busca de serviços públicos em grandes aglomerações urbanas. Em suas várias linguagens e modalidades, a cultura se tornou um bem simbólico tangível e capaz de gerar renda e empregos, contribuindo para o desenvolvimento social, humano e sustentável. O objetivo desse artigo é discutir como se relacionam as dinâmicas da economia e do trabalho local com a cultura advinda do município de Goiás.

Palavras-Chave: economia da cultura; desenvolvimento regional; municípios

\section{Economía y cultura: un estudio aplicado en el municipio de Goiás}

Resumen: Este artículo abordalas relaciones económicas y culturales en una perspectiva de desarrollo local y regional aplicada en el municipio de Goiás, considerado medio en el estado. En 2016, la economía creativa representó aproximadamente el $2.6 \%$ del PIB brasileño, además de presentar un crecimiento de alrededor del $70 \%$ en los últimos diez años. A mayor inversión pública o privada en este nuevo segmento económico, menor será el flujo migratorio de personas que buscan servicios públicos en grandes aglomeraciones urbanas. En sus diversos idiomas y modalidades, la cultura se ha convertido en un activo simbólico tangible capaz de generar ingresos y empleos, contribuyendo al desarrollo social, humano y sostenible. El propósito de este artículo es discutir cómo la dinámica de la economía y el trabajo local están relacionados con la cultura proveniente del municipio de Goiás.

\footnotetext{
${ }^{1}$ Aline Tereza Borghi Leite. Doutora em Sociologia pela Universidade Federal de São Carlos, professora da PUC-GO / Pontifícia Universidade Católica de Goiás, Brasil. E-mail: alineborghi1@gmail.com - https://orcid.org/0000-0002-5702-747X

${ }^{2} J u l i a n o$ Castro Silvestre. Professor do Instituto Tecnológico do Estado de Goiás (ITEGO). Mestre em Desenvolvimento e Planejamento Territorial pela PUC-GO. E-mail: ju.castrosilvestre@gmail.com https://orcid.org/0000-0003-3059-1852
} 
Palabras clave: economía de la cultura; desarrollo regional; municipios

\title{
Economy and culture: a study applied in Goiás
}

\begin{abstract}
This article approaches the economic and cultural relations in a perspective of local and regional development applied in the municipality of Goiás, considered of medium size in the state. In 2016, the Creative Economy accounted for approximately 2.6\% of Brazil's GDP and grew by around $70 \%$ in the last ten years. The more public or private investment in this new economic segment, the smaller the migratory flow of people seeking public services in large urban agglomerations. In its various languages and modalities, culture has become a tangible symbolic asset capable of generating income and jobs, contributing to social, human and sustainable development. The purpose of this article is to discuss how the dynamics of the local economy and work are related to the culture coming from the city of Goiás.
\end{abstract}

Keywords: economy of culture; regional development; town

\section{Economia e cultura: um estudo aplicado no município de Goiás}

\section{Introdução}

Este artigo trata da dinâmica de um território com a sua cultura e as vocações regionais. As relações desse território com os valores morais de uma sociedade, suas crenças, religião e formação social e acadêmica que estruturam os mercados consumidores locais e regionais com seus bens e produtos de arte e cultura. A partir da década de 1990 a economia e a cultura começaram a ser estudadas em conjunto como um campo na grande área das ciências econômicas. E por meio desses estudos que esse artigo irá abordar a relação da economia local com seus bens simbólicos e patrimoniais, a fim de tentar justificar 0 desenvolvimento regional utilizando-se esses bens como uma força motriz da nova economia do século XXI.

O crescimento econômico nunca foi suficiente para gerar desenvolvimento. $\mathrm{O}$ simples aumento do PIB per capita e da renda não contempla a população como um todo e nem promove um desenvolvimento homogêneo. Em muitos casos alarga os graves problemas de desigualdades regionais, não produzindo um igual desenvolvimento humano e social em prol da melhoria de vida da população. Segundo Brant (2009) a cultura como estratégia de desenvolvimento precisa estar inserida no debate político, 
fortalecendo a democracia, a economia e o trabalho no combate às desigualdades.

Benhamou (2007) aponta três fatores que contribuíram para 0 reconhecimento da Economia da Cultura por meio de pesquisas publicadas no Journal of Economic Literature $^{3}:$ i) a geração de fluxos de renda ou de empregos; ii) a necessidade de avaliação das decisões culturais; iii) a evolução da economia política para campos novos. Esses fatores expuseram a cultura num campo econômico no qual seus valores gerados constituíam uma experimentação dos conceitos econômicos fundamentais. Seguindo a tendência de contrapor o modelo fordista de regime de acumulação, cujo dinamismo era oriundo da produção em massa com trabalho pouco qualificado e cujo declínio começou a se desenhar em meados da década de 1970, Harvey (1989) apontava em direção a um novo regime de acumulação sustentável, conhecida por um regime de

\footnotetext{
${ }^{3}$ É uma importante revista científica publicada pela Associação Americana de Economia desde 1969.
}

acumulação flexível que tem a intenção de flexibilizar as relações de regulação do trabalho e principalmente garantir a inovação e diferenciação do produto.

Ao se buscar o tema da economia e da cultura para análise desse artigo o objetivo é discutir a relevância do setor cultural no incremento do setor de serviços local como gerador de emprego e renda num município de médio porte dentro do estado de Goiás, localizado na região Centro-Oeste do Brasil.

O município estudado por esse artigo é Goiás (homônimo do estado), localizado na mesorregião geográfica Noroeste, patrimônio histórico e cultural da humanidade e durante 200 anos capital do estado.O estado de Goiás segundo dados do Instituto Brasileiro de Geografia e Estatística (IBGE, 2015) é a nona maior economia do país e conta com uma população estimada em 2019 de aproximadamente 7 milhões de habitantes. De acordo com o Instituto Mauro Borges de Estatísticas e Estudos Socioeconômicos (IMB, 2017) em 1995, o estado de Goiás possuía 
um valor nominal do PIB (Produto Interno Bruto) na ordem de $\mathrm{R} \$ 14$ bilhões e participação no PIB nacional de 2,05\%. Após 20 anos, o Estado tem um PIB aproximado de $R \$ 170$ bilhões e participação nacional de 2,9\%. Entretanto, levantamento realizada pela Federação das Indústrias do Estado do Rio de Janeiro (FIRJAN, 2018) aponta que pouco mais de $25 \%$ dentre os 246 municípios goianos não têm arrecadações próprias que consigam cobrir suas despesas com 0 custeio da máquina pública, precisando recorrer às transferências intragovernamentais.

Assim, em termos de estrutura textual desse artigo fazemos no primeiro tópico uma apresentação do município de Goiás, objeto de estudo da pesquisa. Em segundo lugar discutimos a problematização que nos levou a discutir o tema e esse município. Em terceiro lugar, relatamos a importância da Economia da Cultura para o estado de Goiás. No quarto tópico são demonstradas as dimensões da economia e do trabalho, por meio de políticas públicas culturais do Governo Federal. Por último as considerações finais desse artigo e as principais impressões e propostas de desenvolvimento regional e local utilizando as vocações culturais e regionais como estratégia para aumentar a renda e emprego.

\section{Apresentação do município de Goiás \\ O município de Goiás, antiga} capital do estado de Goiás por quase dois séculos, é considerado Patrimônio Histórico e Cultural da Humanidade pela UNESCO desde 2001. A população estimada pelo IBGE (2019) aproxima dos 22.645 habitantes, a $49^{a}$ dentre os 246 municípios do estado e sua arrecadação de ICMS (Imposto sobre Circulação de Mercadorias e Serviços) em 2017 representou a importância de $\mathrm{R} \$ 7,1$ milhões correspondendo a posição $69^{a}$ no ranking do estado. Goiás surgiu através da Carta Régia de 11 de fevereiro de 1736 desmembrando-se do município de São Paulo por ordem da coroa portuguesa. No seu espaço urbano segundo o IBGE (2009) existem dois aglomerados: Areias e Ferreiro e cinco distritos: Calcilândia, Buenolândia, Davidópolis, São João e 
Uvá; e um povoado: São João da Lajinha. O IDH-M de Goiás em 2000 apresentou um índice de 0,563 considerado de baixo desenvolvimento. Em 2010 o índice do município de Goiás subiu para 0,709 um aumento de quase $26 \%$ na melhoria das condições de vida da população local, considerando segundo o PNUD (Programa das Nações Unidas para 0 Desenvolvimento) um alto desenvolvimento.

As ruas de pedras, os palácios, museus e construções que remetem aos séculos XVII e XVIII transformaram Goiás - ou Goiás Velho para seus moradores - num lugar reconhecido internacionalmente pelas suas riquezas históricas, culturais e naturais. Um símbolo da cultura vilaboense é a poetisa Cora Coralina (1889-1985) que viveu a maior parte da sua vida às margens do rio vermelho declamando e escrevendo poesias e crônicas, o que a fez adquirir o respeito e admiração de críticos e amantes da literatura brasileira. Sua casa hoje é o Museu Cora Coralina,que conserva mobiliários, relíquias, receitas de comida e suas poesias para exposição. Goiás é um município com várias atividades culturais e artísticas produzidas durante o ano. $O$ destaque é o Festival Internacional de Cinema e Vídeo Ambiental (FICA) que acontece há 20 anos, promovendo à cultura do audiovisual e a relação com a natureza. A Serra dourada tem um parque ambiental, no qual o turista pode apreciar as riquezas rochosas e as espécies típicas do cerrado.

Uma peculiaridade deste município é a concentração de três campi das Universidades Federal de Goiás (UFG), Estadual de Goiás (UEG) e Instituto Federal de Ciência e Tecnologia de Goiás (IFG). Considerado um município de médio porte dentro do estado de Goiás, essa especificidade o torna uma referência de estudos e conhecimento para muitos jovens estudantes que saem de outros locais para ingressarem em cursos técnicos, licenciatura, bacharelado e pós-graduações lato e stricto sensu, sendo que alguns são voltados à preservação do patrimônio 
material e imaterial, gestão cultural e de cinema e audiovisual.

\section{Problematização}

A geração de renda e emprego em pequenos e médios municípios é ínfima ao se comparar com os grandes centros urbanos ou nas regiões metropolitanas. Segundo Sassen (1998) os cidadãos dessas localidades se tornam vítimas e sujeitos passivos da globalização. A expressão "lógica da expulsão" retrata o atual estágio em que vivem os moradores, principalmente, os mais jovens que se veem sem oportunidade de crescimento e emprego. Com baixo investimento público nessas localidades, muitos cidadãos acabam se transferindo para municípios maiores, na tentativa de conseguir uma oferta mais ampla em serviços públicos. Porém este fluxo migratório gera uma pressão sobre as regiões mais desenvolvidas na questão da mobilidade, moradia, saúde, educação e segurança pública.

Como estimular o crescimento econômico da cultura local sem perder a conexão com o mundo global?
Talvez seja esse um dos grandes desafios para os gestores públicos neste século. Não deixar que as cidades fiquem marginalizadas dentro do eixo de crescimento e desenvolvimento, e cujo eixo não seja só econômico, mas o regional, o humano e o sustentável. Investir em outras dimensões de desenvolvimento é permitir que os cidadãos se aproximem dos governos e que possam ter voz ativa. Estimulá-los a proporem soluções e melhorias para o seu território por meio da criatividade advinda das tradições e costumes locais. Entretanto a infraestrutura urbana ainda é um grande entrave para o desenvolvimento local e regional. E a criatividade acaba sendo relegada por não fazer parte da agenda prioritária dos gestores públicos na construção de alternativas para o desenvolvimento local.

O município de Goiás não consegue converter toda sua riqueza história e cultural em bens e produtos culturais. Poucas são as iniciativas para fomentar a cultura e a arte como instrumento de desenvolvimento local e regional. As universidades públicas 
pouco dialogam com a comunidade, os agentes culturais e os atores políticos. Esse cenário aponta para um grave problema: o município de Goiás ao contrário da taxa de crescimento geométrico populacional do estado de Goiás, que ao longo do período entre 2012 a 2018 teve um aumento de aproximadamente $9 \%$, teve um acumulado negativo de $2,38 \%$ no mesmo período analisado.

Ao contrário de municípios de médio porte no Brasil que estimulam o crescimento e 0 desenvolvimento utilizando a atração de empresas, o incentivo ao esporte, ao turismo e à cultura, ou mesmo tornando-se um lugar que concentra universidades e faculdades fomentando a inovação e o empreendedorismo, em Goiás não há uma política pública que incentive a economia. Esse decréscimo populacional é uma resposta a qual as políticas públicas sociais, precisamente em educação, cultura e turismo não estão conseguindo inibir o fluxo migratório da população local para os grandes centros urbanos.

A cidade e o espaço urbano têm de ser criativos, ao proporcionar uma inteligência territorial compondo uma gama de conhecimentos tecnológicos e inovadores (DALLABRIDA; COVAS; COVAS, 2017). Nesse panorama, a cultura constitui-se como um elemento de considerável importância para o desenvolvimento econômico e social das cidades. O Brasil das "belasartes", da música erudita e das expressões culturais, que estava restrito a pequenos grupos, tem se descoberto, à medida que mais grupos sociais produzem e consomem cultura resgatando as origens históricas e culturais de cada região e transformando este patrimônio histórico e cultural em bens e valores simbólicos.

Na visão de Dallabrida e Ferrão (2016) a vertente cultural é o local de apropriação do território pelo cidadão, a valorização da regionalidade cultural ao espaço ocupado. O desafio a ser enfrentado pelos gestores públicos e moradores destas pequenas e médias cidades goianas é buscar soluções criativas e empreendedoras que possibilitem diminuir o fluxo migratório destes cidadãos para grandes centros urbanos. 
A terceira Conferência das Nações Unidas sobre Moradia e Desenvolvimento Urbano e Sustentável (Habitat III), realizado na cidade de Quito no Equador em 2016, reconheceu que em 2050, cerca de $70 \%$ da população mundial viverá em centros urbanos ocasionando um aumento por demandas nas áreas da habitação, emprego, saúde, segurança e educação. Esses dados corroboram a problemática dessa pesquisa ao considerar os pequenos territórios como espaço apropriado para desenvolverem novos modelos de negócios e empreendimentos, os quais podem permitir uma maior interação e conexão dos atores locais com a sua região.

A metodologia dessa pesquisa teve como fundamento uma revisão bibliográfica dos principais autores que discutem a cultura, a economia e o desenvolvimento regional. Buscou-se uma análise de dados primários de institutos de pesquisa, como o IBGE e - IMB cujos resultados serviram para embasar este estudo que tenta mostrar a economia da cultura como uma nova e possível alternativa de desenvolvimento local e regional.

\section{Importância da economia cultural no estado de Goiás}

Trabalhar as cidades contemporâneas é entendê-las dentro da nova realidade pós-moderna. É analisar o contexto sociocultural nas quais estão inseridas. Identificar novas opções de desenvolvimento partindo de uma ideologia de "indivíduo singular". Mas, dentro desta singularidade onde as pessoas se comunicam quase que instantaneamente, percebe-se que a cultura de massa estimula à prática do igual, conforme Jameson (2006). Essa "imitação" ou padronização de ideias e serviços leva as cidades a adotarem discursos criativos como se estes fossem a solução para os problemas urbanísticos, sociais e econômicos do território. Tony Blair no início da década de 1990 do século XX estimulou o desenvolvimento de uma nova ordem econômica na Inglaterra, apoiando empresas e negócios cujo trabalho fosse desenvolvido sob a ótica da criatividade e inovação. O 
surgimento de clusters criativos permitiu que algumas cidades se tornassem "polos criativos mundiais".

Em Goiás, de acordo com o censo 2010 do Instituto Brasileiro de Geografia e Estatística (IBGE) cerca de $40 \%$ da população do estado reside na região metropolitana de Goiânia (capital do Estado). Essa concentração populacional afugenta munícipes de pequenas cidades, pois não se veem perspectivas profissionais para o seu desenvolvimento.

Numa recente entrevista divulgada no site do Ministério da Cultura, John Newbigin, fundador da Creative London, expôs seu raciocínio sobre o desenvolvimento de novos mercados e serviços baseados na capacidade intelectual do indivíduo, no qual podemos destacar: i) "talento está em toda parte, mas a oportunidade não"; ii) "cada cidade, cada região, cada país é diferente e tem de ser construído em suas próprias tradições criativas, suas habilidades, sua herança, sua cultura".Somente essas duas afirmações extraídas desta entrevista, permite-nos dizer que a Cultura pode ser tratada como um novo eixo de desenvolvimento regional. Mas, para que aconteça esse fomento à criatividade e inovação, os municípios precisam criar condições para seu cidadão, estimular a arte e cultura junto com outras pessoas, formando uma conexão em comum de serviços e produtos advindos da intelectualidade.

Para uma melhor compreensão e análise deste trabalho é importante pontuar a diferença entre desenvolvimento e crescimento. Bugs e Bassan (2013) propõem o desenvolvimento como resultado de melhorias no bem-estar de uma população. O crescimento está relacionado ao índice quantitativo referendado pelo seu PIB. Amartya $\mathrm{Sen}^{4}$, Prêmio Nobel de Economia fez

\footnotetext{
${ }^{4}$ Sen é um economista indiano que além de atuar em importantes universidades da Índia, Inglaterra e EUA, ocupou papel importante no Banco Mundial e ganhou grande projeção ao ser laureado com o Prêmio Nobel de Economia no ano de 1998. Também é de sua autoria o IDH - Índice de Desenvolvimento Humano -, que foi adotado pela ONU e se consolidou como a principal referência para medir o nível de desenvolvimento de determinado território.

Fonte: Oliveira, V.L. Liberdade e Poder em Amartya Sen: uma leitura crítica. Disponível em:

https://www.revistas.unijui.edu.br/index.php/de senvolvimentoemquestao/article/view/135/91. Acesso: 15 set. 2018.
} 
uma relação entre liberdade e

Estatísticas

e

Estudos

desenvolvimento apontando que somente indicadores econômicos não suprem a dignidade humana. Na visão de Sen (1999), a liberdade humana é conseguida também pelo fortalecimento de indicadores sociais (educação e saúde) além da liberdade de escolha.

Contudo governos e sociedade não conseguem se libertar da falta de criatividade em áreas sociais, a qual gera uma estagnação no desenvolvimento social do país. Sobre essa afirmação, Furtado (1984, p.51) cita "as forças que alimentam a capacidade criativa da sociedade em todos os planos, forças que entre nós têm profundas raízes regionais". E a criatividade é considerada a principal matéria-prima da Economia da Cultura.

Essa regionalidade terá protagonismo neste novo século caso haja políticas públicas que efetivamente procurem estimular 0 desenvolvimento local com foco no cidadão e naquilo que é produzido nestes locais. Informe Técnico no 10/2018 do Instituto Mauro Borges de "criatividade como uma poderosa ferramenta para os momentos de crise além de servir para a diminuição das desigualdades sociais" (p.1). Partindo dessa análise Dallabrida, Covas e Covas (2017) no seu artigo apontam o conceito de "região inteligente" àquelas que propiciam um ambiente de conhecimento e ideias estimulando a aprendizagem. Nesta mesma linha de raciocínio Reis (2007) afirma que a criatividade como é posta aqui no Brasil sem nenhum modelo educacional e isoladamente, não há nenhum proveito para a economia.

Ao se discutir a importância da aplicação dos recursos públicos na cultura e consequentemente no desenvolvimento do estado, Brant (2009, p. 32-33) afirma:

As dinâmicas socioculturais surgem como possibilidades concretas de ampliar o espaço público e oferecer novas dinâmicas de sociabilização e participação nas decisões da comunidade e da sociedade como um todo. Uma democracia direta, porém, resultante de uma teia de diálogos e conversações. Esta visão se contrapõe ao atual modelo onde os espaços de construção e de participação da vida política estão cada vez mais restritos e contaminados por lógicas corporativas. $O$ incentivo ao debate 
público, a necessidade de compartilhar decisões com o Estado, a criação de uma esfera pública não estatal e a participação estimulada em todos os espaços, formais, informais, institucionais, autônomos, governamentais, são pontos fundamentais para 0 estabelecimento de políticas baseadas na cidadania cultural.

De acordo com Hermet (2002), a cultura possibilita a geração de riquezas e empregos locais em contrapartida às padronizações da Indústria Cultural advinda dos Estados Unidos, Japão e Europa. O mesmo autor cita "o capital social" como elemento eficaz na capacidade de desenvolver "repertórios" em cada localidade respeitando as suas origens e valores étnicos.

Dados da FIRJAN - Federação das Indústrias do Estado do Rio de Janeiro (2014) apontam dados expressivos da Economia da Cultura ou Colaborativa. Em 2013 as atividades econômicas que fazem parte deste segmento representaram 2,6\% do PIB do Brasil ou 126 bilhões de reais gerados pelos empreendedores da área, apresentando um expressivo crescimento de $70 \%$ nos últimos dez anos.
A nova economia do século $X X I$ passa pelas transformações nas profissões. Algumas poderão ser dizimadas e outras surgirão. Os produtores culturais são aqueles profissionais que têm a missão de fazer acontecer o espetáculo, o evento e os serviços inovadores ligados à indústria criativa. A região e o território são espaços urbanos que terão impacto maior nesta nova economia, pois a matéria-prima para a geração destas riquezas culturais passa pelos estudos destes territórios e toda a sua raiz cultural, artística e histórica. É a transnacionalização do território.

Mas, a percepção que se tem da realidade econômica destes municípios e cuja tese de doutorado de Reis (2011) corrobora, apontam para que os perfis destas cidades ditas criativas são mais excludentes e segregadoras em vista de outras "não criativas". De acordo com a autora, "bolsões de criatividade" são gerados em confronto ao pensamento de desenvolver uma política pública, cujo objetivo interligasse toda a cadeia de produção dos municípios, levando à criatividade não para pequenos nichos, 
mas também para dentro das escolas, dos segmentos organizados e da classe política.

De acordo com Hermet (2002), a cultura possibilita a geração de riquezas e empregos locais em contrapartida a padronizações da Indústria Cultural advinda dos Estados Unidos, Japão e Europa. O mesmo autor cita "o capital social" como elemento eficaz na capacidade de desenvolver "repertórios" em cada localidade respeitando as suas origens e valor étnicos. A Economia da Cultura movimenta uma gama de serviços, emprega milhares de pessoas e gera emprego e renda nas cidades.

Zukin (2000) reverbera a importância do desenvolvimento das carreiras criativas como fator de expansão da valorização criativa:

Carreiras novas e em processo de expansão no setor de serviços tornam a infraestrutura crítica especialmente visível nesse processo de valorização cultural. Não se trata de líderes das sociedades históricas locais; há também profissionais de museus, assessores de coleções de arte de empresas, funcionários de galeria de arte e curadores independentes. [...]. Sua atividade, todavia, constitui uma categoria cultural que, por sua vez, ajuda a constituir o sistema de produção de uma cidade pósmoderna (cf. SAHLINS,1976, p.185 apud ZUKIN, 2000, p.90).
Este novo cenário social e econômico do mundo globalizado, no qual o segmento de serviços atinge uma maior fatia do PIB (Produto Interno Bruto) em detrimento à indústria, permite que os gestores e os munícipes invistam em aprimoramento e qualificação profissional dentro da área da Economia Criativa. "À medida que mais pessoas trabalham na economia de serviços, podemos esperar que elas separem suas identidades "reais" das formas de produção nas quais trabalham" (ZUKIN, 2000, p.99).

Em Goiás, segundo IMB (2018), a economia goiana é representada em quase $7 \%$ dentro do segmento cultural e criativo. $\mathrm{Na}$ perspectiva de novos desafios a Economia da Cultura se configura como uma nova oportunidade de desenvolvimento econômico e social para a população que vive, principalmente, em pequenos municípios, nos quais a cultura, as artes e 0 turismo podem ser alternativas de empreendedorismo cultural. 


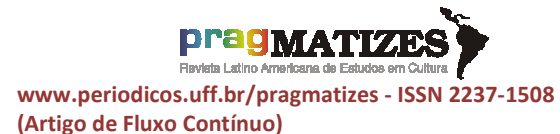

(Artigo de Fluxo Contínuo)

\section{Resultados apurados}

O IBGE (2010) classifica, segundo o seu atlas geográfico, o porte dos seus municípios por habitantes. Então, localidades com até 20 mil habitantes são classificados como municípios de pequeno porte e entre 20 a 50 mil habitantes, de médio porte. Entretanto Sposito (2006) define que além do número de habitantes, os municípios são providos de várias escalas locais e regionais, como 0 tamanho territorial, a influência exercida, a divisão do trabalho e a estrutura da rede urbana como variáveis plausíveis de serem consideradas na classificação de um município. Santos (1979) exprime a sua opinião sobre as pequenas localidades:

A maioria dos estudos urbanos, em países subdesenvolvidos, se interessa de preferência pelas cidades grandes, principalmente pelo fenômeno da macrocefalia. Todavia, se considerarmos com atenção tanto as estatísticas como a realidade, vemos perfilar-se outro fenômeno urbano, o das cidades locais que, ao nosso ver, merece tanto interesse quanto o precedente [...] Poderíamos definir a cidade local como a aglomeração capaz de responder às necessidades vitais mínimas, reais ou criadas, de toda uma população, função esta que implica uma vida de relações. (SANTOS, 1979, p.69-71).
No Brasil, em especial, os municípios de pequeno porte não conseguem competir em dinamicidade, oferta de serviços e empregos se comparado a um grande município ou metrópole. Iniciativas empreendedoras na agricultura, na economia da cultura e na realização de eventos esportivos são consideradas atitudes econômicas, que fazem movimentar o município de pequeno porte atraindo uma grande quantidade de pessoas vindas de fora do município.

Para entender a dinamicidade do município de Goiás, objeto dessa pesquisa, nas dimensões da economia e do trabalho, buscou-se uma fundamentação estatística baseado no Índice de Desempenho do Município (IDM). Esse índice segundo o IMB (2017) é uma medida sintética de parte do contexto socioeconômico dos municípios em seis áreas de atuação: Economia, Educação, Infraestrutura, Saúde, Segurança e Trabalho. São ao todo 37 variáveis selecionadas para conferir o desempenho dos municípios goianos. O objetivo do índice é facilitar o diagnóstico e a comparação do desempenho dos municípios, bem 
como avaliar os resultados e subsidiar o planejamento das ações dos governos ao longo do tempo.

A dimensão Economia do Índice de Desempenho dos Municípios (IDMEconomia) é calculada por meio de média aritmética simples dos scores padronizados de 0 a 10 das seguintes variáveis: valor adicionado (renda gerada) do setor agropecuário; valor adicionado do setor industrial; valor adicionado do setor de serviços; PIB per capita - soma dos bens e serviços finais produzidos no município dividida pelo número de habitantes; evolução do PIB nos dois anos anteriores medida de avaliação do crescimento da economia; percentual dos recursos próprios do município na composição da receita total - medida de independência financeira/tributária do município. Na dimensão trabalho são as seguintes variáveis analisadas: empregos formais entre a população de 18 a 64 anos - nível de formalização do mercado de trabalho da população em idade ativa; remuneração média dos trabalhadores - nível de remuneração média do mercado formal de trabalho; nível de escolaridade dos trabalhadores do mercado formal - trabalhadores com formação de nível médio ou superior; variação do número de empregos formais - evolução dos postos de trabalho formais nos dois últimos anos.

Os dados levantados por essa pesquisa podem observar, conforme 0 gráfico 1 abaixo que o município de Goiás apresentou um aumento aproximado de $35 \%$ na dimensão trabalho entre os anos de 2016 a 2018. Esse aumento tem relação direta com o nível de escolaridade dos trabalhadores locais e o aumento na geração de postos de trabalho. Porém esses trabalhadores pouco estão ligados diretamente ao segmento criativo e cultural. O número de empregos formais subiu de 3152 para 3610 entre 2016 a 2018, um aumento de $14,5 \%$.

$\mathrm{Na}$ dimensão economia conforme o gráfico 1, o IDM dessa dimensão caiu de 1,78 para 1,11 um decréscimo de $37,6 \%$. Esse dado demonstra que a economia local do município de Goiás não conseguiu acompanhar o aumento no IDM Trabalho. A economia não gerou 
riquezas suficientes para alavancar a distribuição de renda e nem o PIB municipal. Outra observação sobre esses dados pode levar em conta que as poucas opções de comércio, serviços e infraestrutura no município, vêm estimulando os moradores a gastarem seus rendimentos em outras regiões com mais infraestrutura na área do comércio e serviços.

Gráfico 1 - Índice de Desempenho do Município de Goiás - dimensão: Economia e Trabalho

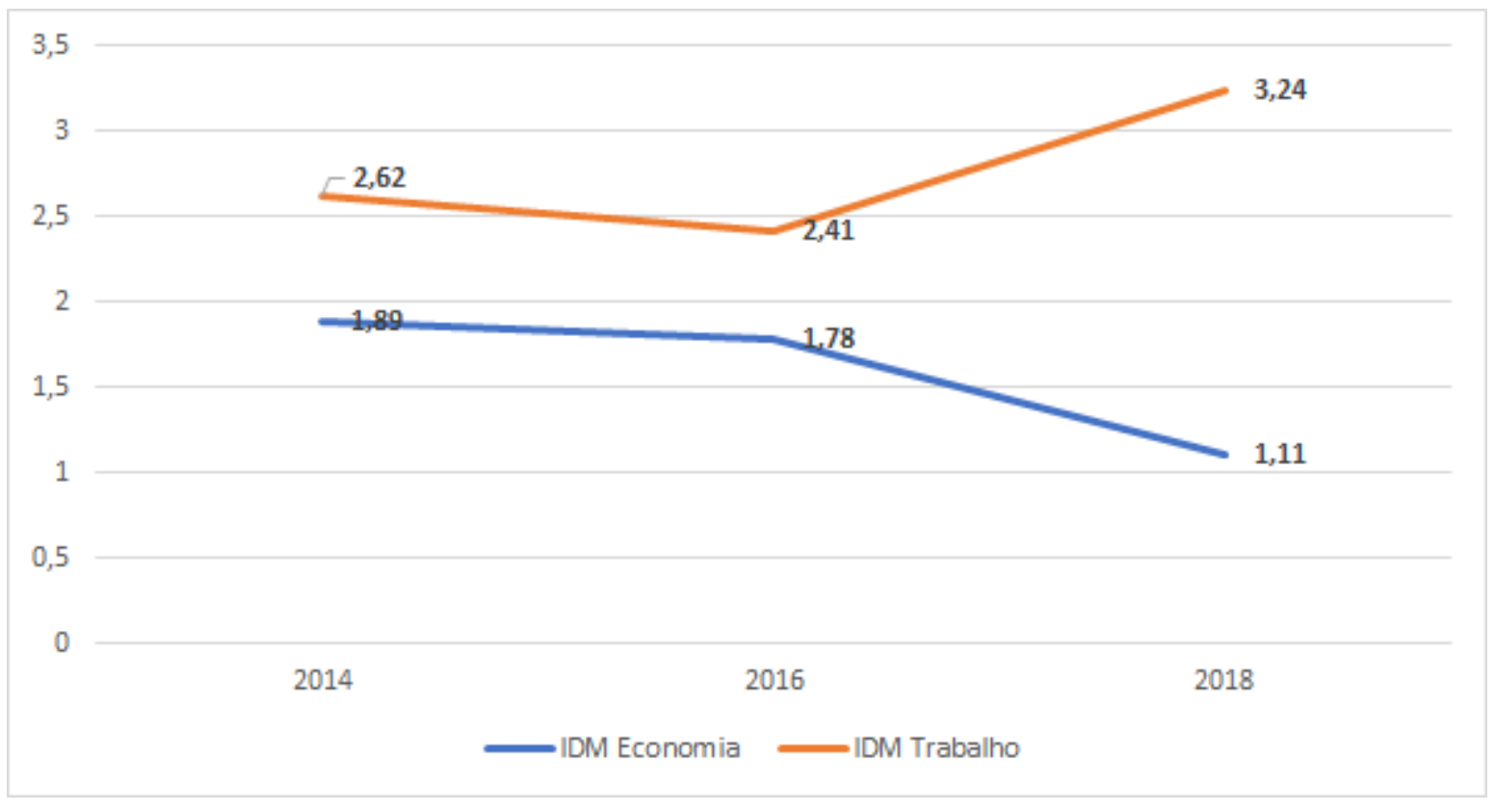

Fonte: IMB/Segplan. Elaboração dos autores

$\mathrm{Na}$ evolução dos empregos formais, o gráfico 2 demonstrou um crescimento entre 2012 a 2014 na ordem $37 \%$ e após dois anos uma retração de $8 \%$. Ao se fazer uma comparação com o gráfico 1, a oferta de vagas de empregos na atividade econômica de serviços oscila para cima e para baixo, a partir de 2009 até 2016. Há momentos de aceleração nas contratações e outras de recuo. Esse fato demonstra que a economia mesmo local sente os efeitos globais da desaceleração econômica do Brasil. Mesmo assim, o setor de serviços em 2016 representou 72\% 
dos empregos formais no município. $\mathrm{O}$ setor agropecuário com 11\%, a indústria com $9 \%$ e administração pública com $8 \%$ retratam 0 desempenho da oferta de empregos em Goiás. No período analisado de
2003 a 2016, o setor de serviços em Goiás cresceu $108 \%$ no número de empregos gerados, pelo fato de ter uma economia cultural e turística que abarca o segmento de serviços.

Gráfico 2 - Evolução dos empregos formais em cada atividade econômica - Goiás (2003-2016)

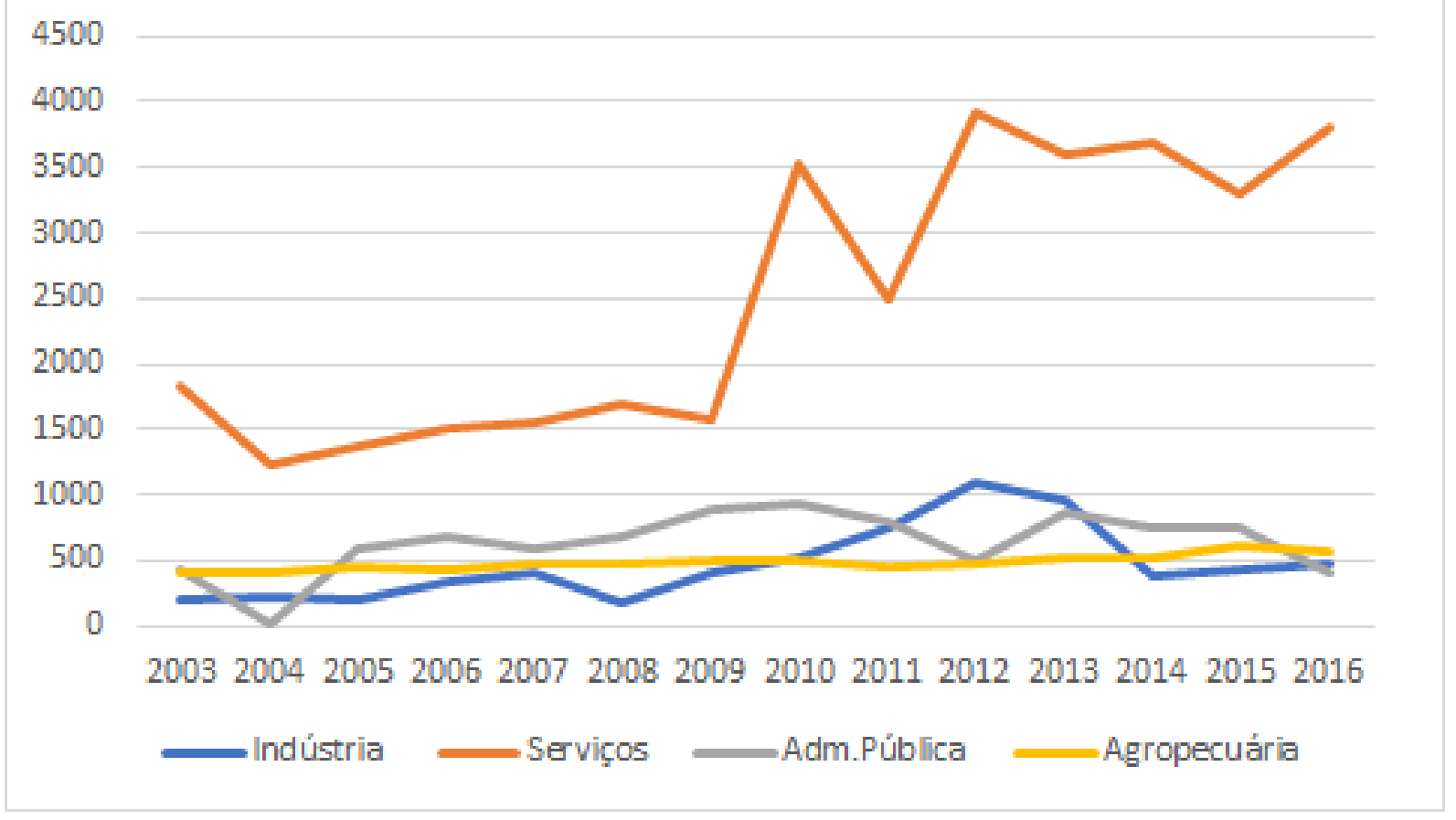

Fonte: IMB/RAIS Elaboração dos autores

Apesar de ter uma ótima variável no nível de escolaridade dos seus trabalhadores, entre 2014 a 2016, a variável remuneração caiu de 2,3 para 1,57 o que pode explicar em parte o IDM na dimensão trabalho. E a variação de empregos formais também caiu, talvez sentindo os efeitos da crise econômica brasileira.

O município de Goiás oferece todas as condições territoriais culturais e históricas para melhorar o seu 
desenvolvimento por meio da economia da cultura. A existência de sítios arqueológicos, museus, palácios e igrejas favorecem a economia local. Tanto a prefeitura quanto o Estado precisam fomentar políticas públicas que visem à formação de agentes culturais capacitados a pensar Goiás como patrimônio histórico e cultural da humanidade. Os shows e festivais são importantes para o município, porém o efeito multiplicador para os seus cidadãos se torna quase pequeno, em razão de não contemplarem a mão de obra local no planejamento e organizações destes eventos e de não investirem na capacitação dos trabalhadores culturais neste município.

Dados do Sistema Nacional de Cultura (SNC) apresenta o município de Goiás cadastrado nesse sistema cultural do MinC. A data de homologação aconteceu no dia 17 de setembro de 2013 no diário oficial da União. Com a inserção de Goiás no SNC, o próximo passo seria a criação de uma lei específica determinando a criação do Sistema Municipal de Cultura (SMC). No mesmo ano, em dezembro, a prefeitura sancionou a lei 032, aprovada pela Câmara Municipal, a qual cria o SMC instituindo programas, projetos e ações para a promoção das políticas públicas culturais no âmbito municipal. Nesta lei criou-se o Conselho Municipal de Política Cultural e o Fundo Municipal 
de Cultura. Em abril de 2014, a prefeitura nomeou os componentes deste conselho para um mandato de dois anos através do decreto no 17. Todos estes mecanismos são estímulos importantes para promover 0 desenvolvimento local.

O Programa de Aceleração do Crescimento (PAC) foi criado pelo governo federal em 2007 para promover a retomada do planejamento e execução de grandes obras. Em 2013, o Ministério do Planejamento cria uma linha exclusiva de crédito para os sítios históricos urbanos protegidos pelo IPHAN $^{5}$. Sua forte tradição cultural e histórica permitiu ao município de Goiás ter acesso às verbas federais do PAC cidades históricas conforme mostra o gráfico 3. 


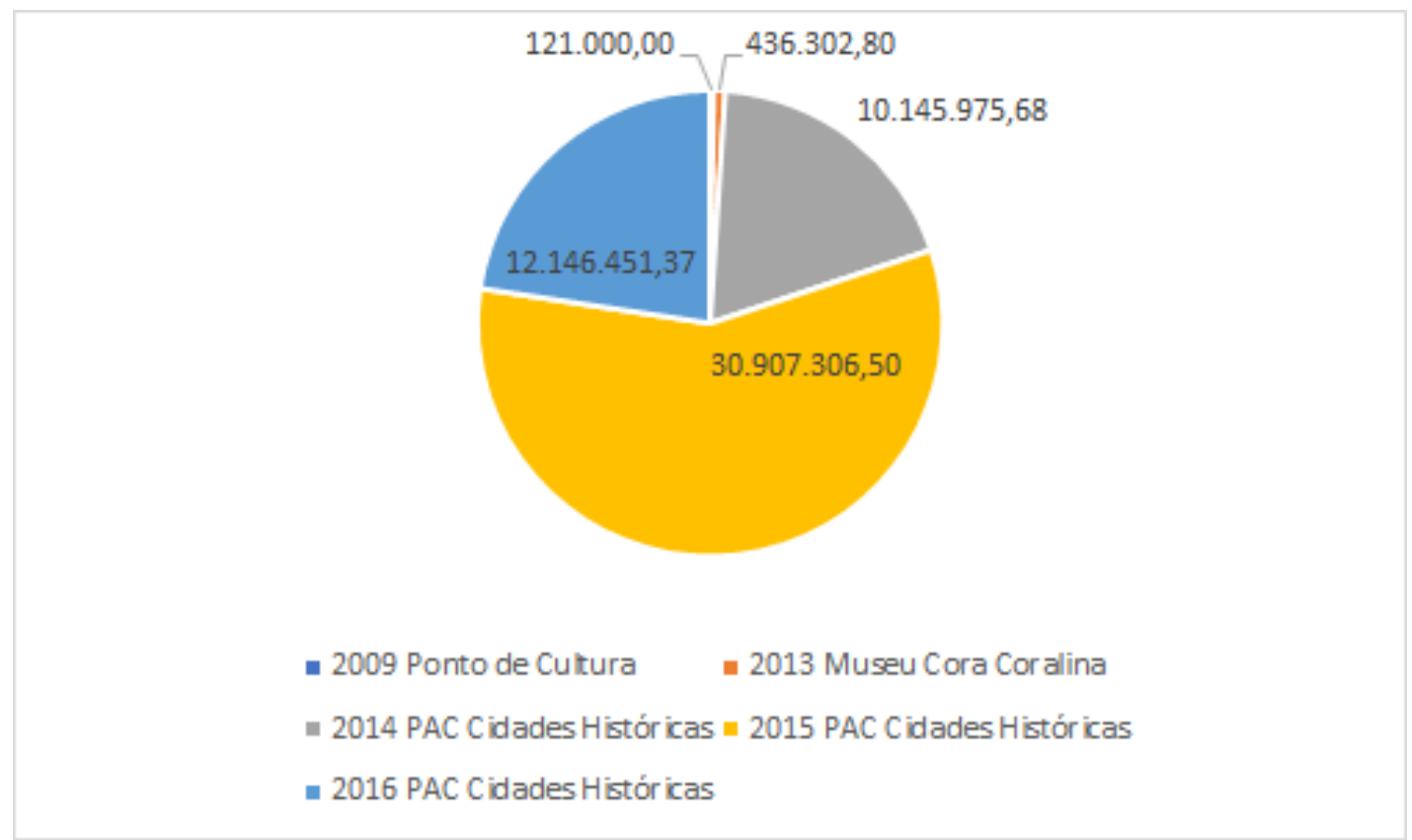

Fonte: Portal da Transparência Brasil/SIAFI e SICONV. Elaboração dos autores

No período de 2003 a 2016 foram registrados no portal da transparência da União, aproximadamente, $\mathrm{R} \$ 52,5$ milhões em verbas federais para o município de Goiás. Desse valor 50 milhões de reais foram destinados à reforma do mercado municipal, do cine teatro São Joaquim e a sede da prefeitura. Esses três bens tombados pelo Instituto do Patrimônio Histórico e Artístico Nacional (IPHAN) foram reconstruídos respeitando as origens arquitetônicas dos séculos XVIII e XIX. O museu de
Cora Coralina recebeu verbas para sua conservação, curso de formação e criação de um DVD com obras da poetisa, segundo 0 portal da transparência. O ponto de cultura Botina Mateira recebeu verbas para implantar sua sede e desenvolver ações culturais dentro do programa Cultura Viva do MinC. A restauração e preservação destes bens é um estímulo para seus moradores e turistas que visitam Goiás e trazem recursos que fazem movimentar a 
Gráfico 2 - Despesas Municipais na função orçamentária cultura - Goiás (2003-2014)

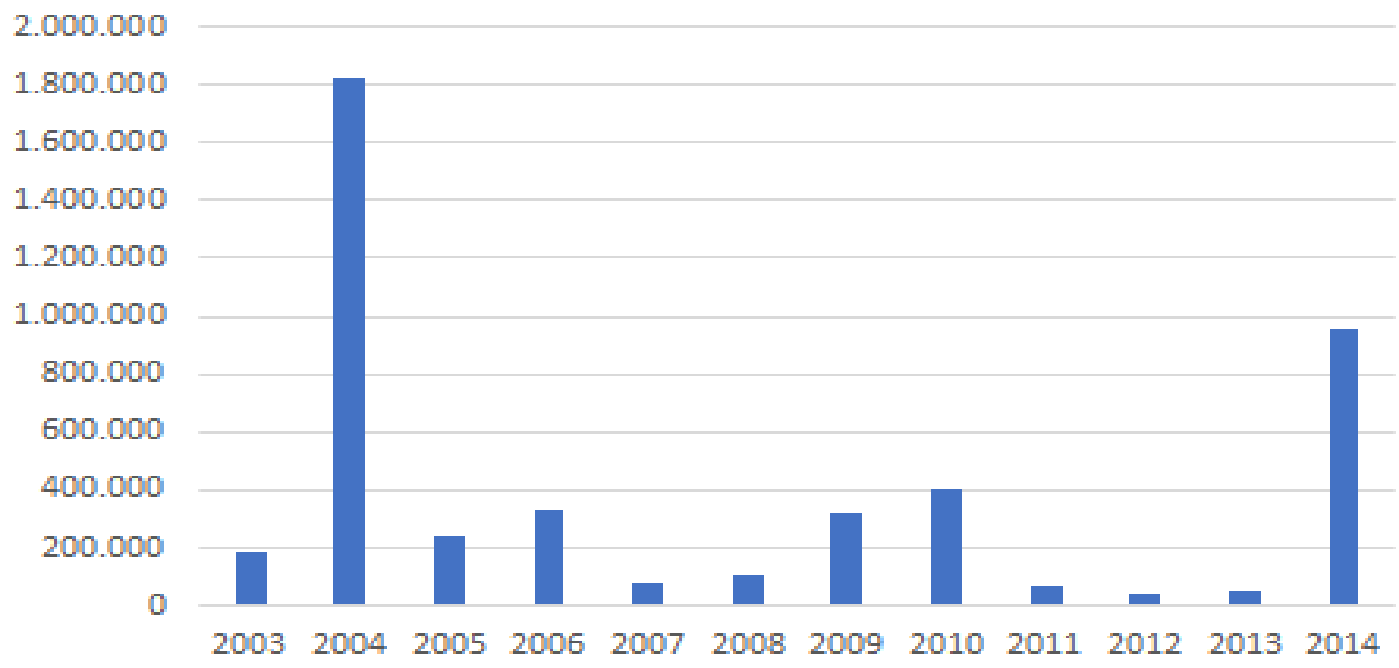

Fonte: IMB/Segplan. Elaboração dos autores

No gráfico 4 as despesas municipais de Goiás entre os períodos de 2003 a 2014 retratou uma excepcionalidade nos anos de 2004 e 2014 com gastos de quase $R \$ 1,8$ milhão e $R \$ 1$ milhão, respectivamente. Nas despesas de 2004 esse valor representou 10\%, e em 2014 1,7\% das receitas municipais. Neste mesmo período as receitas municipais aumentaram em quase $200 \%$, porém as despesas com a cultura não acompanharam esse crescimento. Nos demais anos da pesquisa, a média de gastos com a cultura representou aproximadamente $0,60 \%$ das receitas municipais.

\section{Considerações finais}

Numa economia globalizada as dinâmicas culturais, econômicas e territoriais numa escala local e regional disputam espaço e relevância com os mercados globais. A massificação do uso das tecnologias de informação e comunicação proporcionaram à 
sociedade esse contato com culturas de diversos países. Esse artigo acadêmico tentou contribuir para uma reflexão dos atores sociais e políticos locais, a fim de valorizar os seus recursos materiais e imateriais oriundos das tradições territoriais e culturais, a favor de um desenvolvimento regional que possa estimular à melhoria da qualidade de vida e do crescimento econômico no estado de Goiás.

Essa valorização dos costumes e hábitos culturais locais como instrumento de promoção ao desenvolvimento tem sido gradual e lento. A ausência da profissionalização desses atores sociais locais envolvidos com a economia da cultura é um fator que contribui para esse lento desenvolvimento econômico e social. Atuar nessa atividade como explica Brant (2009) é exigir desse profissional conhecimentos que vão além dos específicos da cultura. É entender o mercado que está inserido, numa visão holística e crítica, que o faça dialogar com todas as partes envolvidas nessa cadeia de produção.
As políticas públicas culturais estabelecidas na CF de 1988 e posteriormente em estados e municípios é um desses instrumentos capazes de promover 0 desenvolvimento local de maneira integrada entre as regiões. Seja por meio da promoção da diversidade cultural e da formação de uma identidade local e regional, as políticas públicas implementadas por estados e municípios precisam "ultrapassar os limites da pasta da cultura e envolver o setor privado e a sociedade civil" (REIS, 2007, p. 140) na intenção de aperfeiçoar esse instrumento político num contexto de coletividade e união entre os atores locais.

Esse novo papel da cultura como estratégia de desenvolvimento regional permite aos municípios e por conseguinte ao Estado de Goiás, propor projetos e empreendimentos culturais para alavancarem a economia local. Porém observa-se uma ausência de infraestrutura institucional e de governança que os inibem a propor projetos culturais que contemplem a diversidade cultural e a identidade local. Poucos são os 
empreendimentos culturais que valorizam a identidade $e$ as características locais. Segundo Reis (2007) esse processo de exclusão das minorias e das suas manifestações culturais é resultado dos privilégios obtidos pelas elites nacionais vindas dos séculos passados. Além disso, a falta de pessoas qualificadas nesses municípios para pensarem e trabalharem alternativas para a promoção do desenvolvimento regional ficou bem evidente, ao constatar que os esforços do poder público e da sociedade ainda continuam na questão industrialização, para alcançar uma qualidade de vida e bem-estar social.

Os desafios da economia da cultura para a promoção do desenvolvimento regional ultrapassam a negação da cultura como alternativa para o desenvolvimento. A certeza agora é provocar o debate de como e em que forma essas novas atividades econômicas serão exploradas e utilizadas com o objetivo de gerar renda e emprego no município de maneira sustentável. O papel de estrategista na formulação de planos de desenvolvimento e crescimento local é dos municípios e do Estado. A importância da integração e da união dos seus stakeholders constituem peça fundamental para a elaboração de um planejamento discutido com base nas vocações e nas habilidades dos seus moradores e do seu território.

Afinal, ao propor esse tema buscou-se uma apropriação da cultura além do entretenimento e da diversão. Discutir cultura é aprofundar o debate acerca da profissionalização da classe cultural e das inúmeras possibilidades de se trabalhar a cultura numa perspectiva de desenvolvimento. A preocupação com os pequenos $\mathrm{e}$ médios municípios e os seus desafios para o novo século baseou-se no registro de que aproximadamente $80 \%$ dos 246 municípios goianos têm população abaixo dos $30 \mathrm{mil}$ habitantes. Além disso, o estado de Goiás apesar de todos os esforços de industrialização carrega uma forte vocação para a economia primária baseada em grãos e carne bovina.

São economias pouco dinâmicas e geradoras de empregos com baixo valor agregado e de 
qualificação, reduzindo a renda per capita da população.A administração pública constitui uma outra fonte de renda quando se propõe a empregar as pessoas de pequenas localidades prejudicando as despesas da prefeitura, ao invés de criar condições de se empreender utilizando políticas públicas sociais. Sem perspectivas de empregos nos pequenos municípios, é natural o fluxo migratório para os grandes centros urbanos, aumentando a demanda por atendimentos nos serviços públicos.

Essa foi a razão deste estudo e esperamos que possa contribuir como fonte de informações e estratégias para os gestores públicos, sociedade, estudantes e profissionais da cultura. Num país multicultural como o Brasil, é importante que estes atores sociais e políticos comecem a perceber que a economia da cultura pode ser uma alternativa para promoverem 0 desenvolvimento local e também intermunicipal, ao valorizar os municípios vizinhos construindo uma rede de conexões com o objetivo comum de movimentar a economia e o trabalho com geração de renda e emprego para os seus munícipes.

\section{Referências bibliográficas:}

AVELAR, Rômulo. O avesso da cena: notas sobre produção e gestão cultural. Belo Horizonte: Ed. do Autor, 2013.

BENHAMOU, F. A economia da cultura. Cotia, SP: Ed. Ateliê, 2007.

BRANT, L. O poder da cultura. São Paulo: Peirópolis, 2009.

BRASIL. Constituição (1988). Constitui ção da República Federativa do Brasil. Brasília, DF: Senado Federal: Centro Gráfico, 1988.

BUGS, J; BASSAN, D. A busca do desenvolvimento através da cultura. Colóquio - Revista do Desenvolvimento Regional - Faccat, v. 10, n.1, p. 147-162, jan./jun. 2013.

CALABRE, L. Políticas públicas culturais de 1924 a 1945: o rádio em destaque. Estudos Históricos. Rio de Janeiro, n. 31, p.161-181, 2003

CUNHA FILHO, F. H. Teoria e prática da gestão cultural. Fortaleza: UNIFOR, 2002.

CUNHA, M. H. M. da. Gestão cultural: profissão em formação. Belo Horizonte: Duo Ed., 2007.

DALLABRIDA, V. R.;FERRÃO, J. Governança territorial em arranjos cooperativos institucionais e organizacionais: aportes teóricometodológicos e avaliação de experiências brasileiras e portuguesas. In: BADALOTTI, R. M.; COMERLATTO, D. (orgs.). Território, 
territorialidades e estratégias de desenvolvimento regional. Passo Fundo, RS: IMED, 2016. p.28-46.

DALLABRIDA, V. R.; COVAS, M. M. C. M.; COVAS, A. M. A. Inovação, Desenvolvimento e Espaço Urbano: uma relação necessária mas não suficiente. Revista Brasileira de Estudos Urbanos e Regionais. Recife, v. 19, n. 2, p.360-378, 2017.

FEDERAÇÃO DAS INDÚSTRIAS DO RIO DE JANEIRO - FIRJAN. Criação de Municípios: mais impostos e menos serviços à população (2018) Disponível em: http://www.firjan.com.br/publicacoes/pu blicacoes-de-economia/criacao-demunicipios-mais-impostos-e-menosservicos-a-populacao-1.htm Acesso: 1 set. 2018.

FEDERAÇÃO DAS INDÚSTRIAS DO RIO DE JANEIRO - FIRJAN. Mapeamento da Indústria Criativa no Brasil (2014) Disponível em: http://www.firjan.com.br/economiacriati $\mathrm{va/download/mapeamento-industria-}$ criativa-sistema-firjan-2016.pdf Acesso: 10 abr.2018

FREIDSON, E. Para uma análise comparada das profissões: a institucionalização do discurso e do conhecimento formais. Revista Brasileira de Ciências Sociais, v. 11, n. 31, p. 141-154, 1996.

FREIDSON, E. Renascimento do Profissionalismo: teoria, profecia e política. São Paulo: Ed. USP, 1998.

FURTADO, C.Cultura e desenvolvimento em época de crise. São Paulo: Paz e Terra, 1984.
GIL, A. C. Redes cooperativa regionais e governanças. Redes, v. 7, n.3, p. 6184, set./dez. 2002.

HERMET, G. Cultura e desenvolvimento. Petrópolis, RJ: Vozes, 2002.

INSTITUTO BRASILEIRO DE GEOGRAFIA E ESTATÍSTICA - IBGE. Conheça Cidades e Estados do Brasil. Disponível em: http://cidades.ibge.gov.br/xtras/home.p hp?lang=_EN. Acesso: 14 nov. 2017.

INSTITUTO BRASILEIRO DE GEOGRAFIA E ESTATÍSTICA IBGE.Sistema IBGE de recuperação automática: SIDRA. Banco de dados agregados. Disponível em: http://www. sidra. ibge. gov. br/bda/tabela/protabl. asp, 2015. Acesso: 20 out. 2017.

INSTITUTO BRASILEIRO DE GEOGRAFIA E ESTATÍSTICA IBGE.. Estimativas de População 2018. Disponível em: https://www.ibge.gov.br/estatisticasnovoportal/sociais/populacao/9103estimativas-de-populacao. $\mathrm{html} ?=\& \mathrm{t}=0$ que-e. Acesso: 14 out. 2018.

INSTITUTO MAURO BORGES DE ESTATÍSTICAS E ESTUDOS SOCIOECONÔMICOS - IMB. Goiás em Dados 2014. Disponível em: http://www.imb.go.gov.br/viewnot.asp?i d_cad=1209\&amp;id_not=3\&gt.

Acesso: 5 jan. 2018.

INSTITUTO MAURO BORGES DE ESTATÍSTICAS E ESTUDOS SOCIOECONÖMICOS - IMB. Índice de desempenho dos municípios. Disponível em: http://www.imb.go.gov.br\&gt. Acesso: 22 jun. 2017. 
INSTITUTO MAURO BORGES DE ESTATÍSTICAS E ESTUDOS SOCIOECONÔMICOS - IMB. Painel das Profissões 2018. Disponível em: http://profissoes.imb.go.gov.br/profisso es/view/mercado.php. Acesso: 15 jun. 2017.

INSTITUTO MAURO BORGES DE ESTATISTICAS E ESTUDOS SOCIOECONÔMICOS - IMB.

Caracterização da Economia Criativa em Goiás. Informe Técnico n.10/2018. Disponível

em:

http://www.imb.go.gov.br/files/docs/pub licacoes/informes-tecnicos/2018/10caracterizacao-da-economia-criativaem-goias-201806.pdf. Acesso: 30 set. 2018.

JAMESON, F. A virada cultural: reflexões sobre o pós-modernismo. Rio de Janeiro: Civilização Brasileira, 2006.

MARINHO, T. A.. Família e Extensão: para além dos muros da Universidade. Revista Fragmentos de Cultura Revista Interdisciplinar de Ciências Humanas, v. 25, n. 1, p. 15-26, 2015.

MINISTÉRIO DA CULTURA - MINC. Gestor público britânico defende criatividade na economia. Disponível em: http://www.cultura.gov.br/o-dia-adia-da-cultura/-

/asset_publisher/waaE236Oves2/conte nt/gestor-publico-britanico-defende-

criatividade-na-

economia/10883? redirect=http $\% 3 A \% 2$ F\%2Fwww.cultura.gov.br\%2Fo-dia-adia-da-

cultura\%3Fp_p_id\%3D101_INSTANC E_waaE236Oves2\%26p_p_lifecycle\% 3D0\%26p_p_state\%3Dnormal\%26p_p mode\%3Dview\%26p_p_col_id\%3Dco Iumn-1\%26p $p$ col count $\% 3 D 1$

Acesso: 30 out. 2018.
MINISTÉRIO DA CULTURA - MINC. Relatório de economia criativa 2010: economia criativa uma, opção de desenvolvimento. Brasília: Secretaria da Economia Criativa/MinC ; São Paulo: Itaú Cultural, 2012.

MONTEIRO NETO, A.; BRANDÃO, C. A. ; CASTRO, C. N. de (orgs.). Desenvolvimento Regional brasileiro: dilemas e perspectivas neste início de século XXI. Brasília: IPEA, 2017.

REIS, A. C. F. Economia da Cultura e desenvolvimento sustentável: 0 caleidoscópio da cultura. Barueri, SP: Manole, 2007.

SASSEN, S. As cidades na economia mundial. São Paulo: Studio Nobel, 1998.

SEN, A. K. Desenvolvimento como Liberdade. São Paulo: Companhia das Letras, 1999.

SERVIÇO BRASILEIRO DE APOIO ÀS MICRO E PEQUENAS EMPRESAS. Sebrae (2014). Participação das Micro e Pequenas Empresas na Economia Brasileira. Disponível em: https://m.sebrae.com.br/Sebrae/Portal $\% 20 S e b r a e / E s t u d o s \% 20 \mathrm{e} \% 20$ Pesquis as/Participacao\%20das\%20micro\%20 e\%20pequenas\%20empresas.pdf. Acesso: 20 out. 2018.

SERVIÇO BRASILEIRO DE APOIO ÀS MICRO E PEQUENAS EMPRESAS. Sebrae.DataSebrae. Disponível em: http://datasebrae.com.br/pib/\#maiores. Acesso: 30 set. 2018 .

VIEIRA, J. C. Planejamento em Goiás: uma reflexão do Plano Mauro Borges. Revista de Ciências Ambientais e 
Saúde, v.39, n. 1, p. 3-14, jan/mar, 2012.

ZUKIN, S. Paisagem urbana pósmoderna: mapeando cultura e poder. In: O ARANTES, Antônio A (org.). $O$ espaço da diferença. Campinas, SP: Papirus, 2000. 